\title{
A CONSTRUÇÃO IDENTITÁRIA NA FRONTEIRA ENTRE PEDRO JUAN CABALLERO - PARAGUAI E PONTA PORÃ - BRASIL: POR UMA IDENTIDADE TRASNFRONTEIRIÇA
}

\section{IDENTITY BUILDING ON THE BORDER BETWEEN PEDRO JUAN CABALLERO - PARAGUAY AND PONTA PORÃ - BRASIL: FOR A TRASNFRONTEIRIENT IDENTITY}

\section{LA CONSTRUCCIÓN DE LA IDENTIDADEN LA FRONTERA ENTRE PEDRO JUAN CABALLERO - PARAGUAY Y PONTA PORÃ - BRASIL: POR UNA IDENTIDADE TRASNFRONTERIZA}

Jonas Ariel Cantaluppi de SOUZA ${ }^{1}$

\begin{abstract}
Resumo: O objetivo deste artigo é entender a formação da identidade transfronteiriça na fronteira entre Ponta Porã - BR e Pedro Juan Caballero - PY resultante do intenso intercâmbio e relações que ocorrem nesta fronteira. Usar-se-á o conceito de identidade territorial para distinguir as identidades reconhecidas dos dois lados e uma possível identidade transfronteiriça resultante do hibridismo, mestiçagem e trocas culturais singulares presentes neste espaço, assim como entrevistas direcionadas a brasileiros e paraguaios residentes nas duas cidades citadas acima. Faz-se necessário a discussão de território neste estudo, pois a partir dessas concepções se entenderá melhor os conflitos ocasionados a partir do encontro destas nações, com o "outro" o "diferente", assim como o conceito de territorialização, pois é com este processo que serão elaboradas os modos de ocupar e viver neste espaço. Contudo a fronteira segue sua trajetória, nem tudo está integrado e diluído, a diferença afirmase a cada dia, percebe-se que a fixidez das identidades entrou em colapso dando oportunidade ao surgimento de novas identidades.
\end{abstract}

Palavras-chave: Pedro Juan Caballero; Ponta Porã; Identidade transfronteiriça.

ABSTRACT: The purpose of this article is to understand the formation of cross-border identity on the border between Ponta Porã - BR and Pedro Juan Caballero - PY resulting from the intense interchange and relationships that occur on this border. The concept of territorial identity will be used to distinguish the identities recognized on both sides and a possible cross-border identity resulting from hybridism, miscegenation and singular cultural exchanges present in this space, as well as interviews directed to Brazilians and Paraguayans residing in the two cities mentioned above.It is necessary to discuss territory in this study, as from these conceptions it will be better to understand the conflicts caused by the meeting of these nations, with the "other" the "different", as well as the concept of territorialization, because it is with this process that will be elaborated the ways of occupying and living in this space. However, the border follows its trajectory, not everything is integrated and diluted, the difference asserts itself every day, it is clear that the fixity of identities has collapsed, giving opportunity to the emergence of new identities.

Keywords: Pedro Juan Caballero; Ponta Porã; Cross-borderidentity.

RESUMEN : El propósito de este artículo es comprender la formación de la identidad transfronteriza en la frontera entre Ponta Porã - BR y Pedro Juan Caballero - PY como resultado del intenso intercambio y las relaciones que se producen en esta frontera. El concepto de identidad territorial se

\footnotetext{
${ }^{1}$ Mestre e Doutorando em Geografia pela Universidade Federal da Grande Dourados. Artigo escrito durante a realização da dissertação de mestrado no Programa de Pós - Graduação em Geografia na Universidade Federal da Grande Dourados. Email: geoensinopp@gmail.com
} 
utilizará para distinguir las identidades reconocidas en ambos lados y una posible identidad transfronteriza resultante del hibridismo, mestizaje e intercambios culturales singulares presentes en este espacio, así como entrevistas dirigidas a brasileños y paraguayos que residen en las dos ciudades mencionadas anteriormente. Es necesario discutir el territorio en este estudio, ya que a partir de estas concepciones será mejor comprender los conflictos causados por la condició nfronteriza de estas naciones, con el "otro", el "diferente", así como el concepto de territorialización, porque es con este proceso en el que se elaborarán las formas de ocupar y viviren este espacio. Sin embargo, la fronteras i su trayectoria, no todo está integrado y diluido, la diferencia se afirma todos los días, está claro que la fijeza de las identidades se ha derrumbado, dando oportunidad a la aparición de nuevas identidades.

Palabras claves: Pedro Juan Caballero; Ponta Porã; Identidad transfronteriza.

\title{
Introdução
}

\author{
Uma vez sabe como me identifiqué como paraguaia? \\ Foi assim, sabe que me incomoda, esses brasileiros que falam mal do \\ paraguaio, sabe? \\ Incomoda já! Ficam falando que somos mandioqueiros, que não \\ queremos trabalhar sabe. Porque aqui todo el mundo viene, tem lugar \\ pra todo mundo, tem pra "trabalha", aqui é o lugar que se exige \\ menos coisas, você pode trabalhar clandestinamente, você pode entrar \\ e sair livremente, ai eu me ofendi e percebi que me identifico como \\ paraguaia. Por exemplo a Verônica é branca (a irmã) eu sou mais \\ india, porque meu vô é paraguayo mesmo! Meu pai é brasileiro! \\ Carmen, 34 anos, brasileira (para o senso comum) Ensino Médio \\ completo. Pedro Juan Caballero 20/01/2017.
}

A fala de Carmen acima foi citada para problematizar e exemplificar o conflito identitário e territorial, existente na fronteira entre as cidades-gêmeas de Pedro Juan Caballero no Paraguai e Ponta Porã no Brasil.

A formação destes territórios ocorre através da necessidade de criar os limites dos países, contudo, não blindou as relações entre brasileiros e paraguaios que se instalavam na região para a exploração da Ilex Paraguariesis, (erva mate) e do café. Assim, o processo de colonização desta fronteira está relacionado não somente por sua importância econômica, mas também pelo fato da região ser importante para delimitar o território a leste do Paraguai e proteger as fronteiras do oeste brasileiro estabelecendo assim núcleos urbanos para a presença do Brasil nesta direção, logo após o fim da Guerra da Tríplice Aliança (1865 - 1870).

Estudar fronteira no mundo contemporâneo é uma tarefa quase que inevitável no campo geográfico devido à sua presença e relevância na atualidade, igualmente difícil por possuir vários significados e contextos. Os estudos sobre fronteiras se iniciaram com formação dos Estados territoriais na Europa moderna tendo sua concepção desde o ponto de vista, militar estabelecendo limites, demarcando territórios, enfim o front (MARTIN, 1998).

No século XX, Barth vê a fronteira como campo de relações sociais e políticas a partir da apreciação e encontro com diferentes grupos, ou seja, as relações produzidas levando em conta a diferenciação (BARTH, [1969] 1998). Após os processos pós-coloniais e inserção dos movimentos sociais, a fronteira "será compreendida tanto como o lugar da explicitação de diferenças obscurecidas pelas sociedades nacionais e patriarcais pensadas como homogêneas, bem como um espaço de intensos fluxos sociais, hibridismos culturais e configurações de poderes oblíquos" (ALBUQUERQUE, 2010).

Para Martins, a fronteira não se restringe à fronteira geográfica ela pode se apresentar no âmbito: cultural, visões de mundo, espacial, étnicas e principalmente a fronteira do 
humano e deixa explicito que a fronteira é essencialmente o lugar da alteridade (MARTINS, 2009). As relações sociais transcendem desse modo o limite territorial, criando uma relação de interdependência entre as duas cidades, desde o ponto de vista econômico, social e inclusive no tocante as políticas públicas.

O objetivo deste artigo é entender a formação da identidade na fronteira entre Ponta Porã-Brasil e Pedro Juan Caballero-Paraguai a partir das intensas trocas e relações aqui observadas e analisadas. Se usará o conceito de identidade territorial para distinguir as identidades reconhecidas (dominantes) dos dois lados e uma possível identidade transfronteiriça existente e resultante do hibridismo, mestiçagem e trocas culturais ocorrentes neste espaço. Para sustentar este estudo serão utilizados autores, como: Albuquerque (2010); Anderson (1983); Bauman (2005); Castell (1994); Chelotti (2000); Haesbaert (1999, 2004, 2005); Hall (1998); Laclau (1990); Martin (2009); Raffestin (1993); Silva (2000), dentre outros.

A metodologia será a abordagem qualitativa a partir de revisão bibliográfica, observação participante e entrevistas direcionadas aos brasileiros, paraguaios e autodenominados "brasiguaios" 2 nos dois lados da fronteira. Percebe-se que entre as duas cidades identificaram-se referências territoriais e simbólicas construtoras de uma identidade que transcende os limites territoriais, dissolvendo e atenuando a dupla identidade nacional na fronteira.

\section{A identidade territorial}

Antes de iniciar a caracterizar as identidades territoriais de Pedro Juan Caballero e Ponta Porã. Com base na empiria, analisaremos alguns conceitos de identidade a partir de autores das ciências sociais como ponto de partida, para logo assim tentar entender e pensar a identidade fronteiriça.

$\mathrm{Na}$ contemporaneidade existe a necessidade de pensar identidade pelo fato de estar diretamente relacionado com o cotidiano em que nos encontramos, independentemente do lugar ou território em que a iremos adotar, utilizo o termo "adotar" para indicar intencionalmente o caráter construtivo da identidade e indicar que não nascemos com ela, entretanto é criada e formada na representação.

Voltando ao caso da Carmen citada no início do texto, para a identidade paraguaia existir, depende de algo de fora dela, ou seja, outra identidade (neste caso, a brasileira), de uma identidade que ela não é, que seja diferente da paraguaia, mas que, fornece as condições para que ela exista. Assim, a identidade é relacional e marcada pela diferença (WOODWARD, apud SILVA, 2000). Enquanto ao processo excludente de identificação as identidades que não se encaixam na dominante são denominadas de "subclasse" estão exiladas nas profundezas além dos limites da sociedade, essa identidade de "subclasse" seria a ausência de identidade, a abolição ou negação da individualidade, "sendo excluída do espaço social em que as identidades são buscadas, escolhidas, construídas, confirmadas ou refutadas, onde o lixo humano tornou-se um fenômeno mundial" (BAUMAN, [1925] 2005).

Existe um consenso que a identidade é uma construção social e simbólica, entretanto cada grupo social foi criando significados vinculados à sua cultura, religião, etnia, território entre outros.

\footnotetext{
${ }^{2}$ Este termo possui vários significados dependendo da fronteira que se está. Pode referir-se a brasileiros que retornaram do Paraguai em 1985, campesinos paraguaios se referem aos "brasiguayos" como fazendeiros brasileiros que possuem terras no Paraguai e no caso desta fronteira há mais de um significado para "brasiguaio" como veremos adiante.
} 
Não é difícil concordar com o fato de que, do ponto de vista sociológico, toda e qualquer identidade é construída. A principal questão, na verdade, diz respeito a como, a partir de quê, por quem? E para que isso acontece? A construção de identidades vale-se da matériaprima fornecida pela história, geografia, biologia, instituições produtivas e reprodutivas, pela memória coletiva e por fantasias pessoais, pelos aparatos e de poder e revelações de cunho religioso. Porém, todos esses materiais são processados pelos indivíduos, grupos sociais e sociedades, que reorganizam seu significado em função de tendências sociais e projetos culturais enraizados e sua estrutura social, bem como em sua visão de tempo/espaço (CASTELL, 1999, p. 23).

A globalização possui um papel importante para a diluição das identidades no nível local e individual, as transformações nos padrões de produção e consumo levou a uma crise de identidade que Laclau (1990, p.40) chamou de deslocamento, logo argumenta que as sociedades modernas já não possuem um centro criador de identidades fixas, ao contrário, há uma pluralidade nos centros criadores identitários, um deslocamento do centro.

Laclau (1990) argumenta que não existe mais uma única força, determinante e totalizante, tal como a classe no paradigma marxista, que molde todas as relações sociais, mas, em vez disso, uma multiplicidade de centros. Ele sugere não somente que a luta de classes não é inevitável, mas que não é mais possível argumentar que a emancipação social esteja nas mãos de uma única classe. $\mathrm{O}$ autor argumenta, ainda, que isso tem implicações positivas porque esse deslocamento indica que há muitos e diferentes lugares a partir dos quais novas identidades podem emergir e a partir dos quais novos sujeitos podem se expressar (WOODWARD, apud SILVA, 2002).

Os processos históricos que sustentavam a fixidez das identidades entraram em colapso dando oportunidade ao surgimento de novas identidades. É importante destacar o papel das migrações no processo produzindo identidades plurais, mas também identidades contestadas e fortalecidas. Uma vez que não podemos conhecer e partilhar todas as identidades nacionais, idealizamos sobre aquilo que a constitui, buscando autenticar as políticas de identidade através da comunidade imaginada (ANDERSON, 1983).

O caráter homogeneizante da globalização enfraqueceu as identidades nacionais, mas em contrapartida evidencia outras identidades. Segundo Hall (1998, p. 69), as identidades nacionais estão se desintegrando, com resultado do crescimento da homogeneização cultural e do "pós-moderno global". As identidades nacionais e outras identidades "locais" ou particularistas estão sendo reforçadas pela resistência à globalização. As identidades nacionais estão em declínio, mas novas identidades - híbridas - estão tomando seu lugar.

Reconhecendo o avanço do sistema capitalista através da globalização, houve elementos culturais mantidos, no caso paraguaio, por exemplo, os costumes religiosos, a música tradicional paraguaia e o idioma guarani mantendo esses modos de vida para não desaparecer em meio a essa tentativa homogeneizador. Entendendo que essas características socioespacias foram mantidas, e principalmente as culturais, Chelotti (2010) acrescenta:

Acreditamos, então, que ocorre, embora de maneira relativizada, a identificação de certos grupos sociais com uma determinada espacialidade (território, região, lugar) e suas representações simbólicas. Portanto, estaríamos diante da resistência da identidade com perspectiva territorial, principalmente, ainda verificável em sociedades tradicionais que não foram destruídas (CHELOTTI, 2010, p. 173).

As cidades de Pedro Juan Caballero e Ponta Porã, possuem suas características próprias de acordo com suas características materiais e imateriais, construídas a partir das relações sociais produzidas de cada lado, assim essas sociedades construíram suas identidades 
territoriais ancoradas inicialmente na identidade nacional. Mas a partir das relações homem versus meio e sua interação transnacional criou-se na fronteira uma identidade própria, com seus símbolos, bandeiras, pertencimentos, culturas, etnias, etc.

Partimos do pressuposto geral de que toda identidade territorial é uma identidade social definida fundamentalmente através do território, ou seja, dentro de uma relação de apropriação que se dá tanto no campo das ideias quanto no da realidade concreta, o espaço geográfico constituindo assim parte fundamental dos processos de identificação social. [...] De forma muito genérica podemos afirmar que não há território sem algum tipo de identificação e valoração simbólica (positiva ou negativa) do espaço pelos seus habitantes. (HAESBAERT, 1999, p. 172).

Dessa forma, o essencial para este estudo será a análise das identidades a partir da perspectiva territorial construídas a partir do sentimento de pertencimento com dois referenciais territoriais como no caso apresentado.

\section{A identidade territorial na fronteira entre Ponta Porã e Pedro Juan Caballero}

Para iniciar este item partimos da ideia de que a construção da identidade (étnica, territorial, político-cultural) está inseparavelmente associada ás relações de poder simbólicas que se experimentam na fronteira, tendo os símbolos um papel importante de legitimação no processo de quem a constrói ou estão sujeitos.

Dessa forma o que se percebe com o poder simbólico é que de certa forma este impõe o mundo social, naturalizando e disfarçando esse poder. Como no caso da Carmen o fato de perceber a representação negativa que os brasileiros têm em relação aos paraguaios passa pelo simbólico: disfarçado, no entanto ela se sente excluída nesta relação de poder que diferentemente do poder econômico, político, que pode ser intencional, o poder simbólico pode ser disfarçado por parte de quem exerce.

É importante destacar a complexidade que envolve discutir o território (envolve conflitos, e tensões, desde sua criação à implementação e legitimação), identidade (pelo caráter dinâmico, relacional, polissêmico) e fronteira (devido à sua porosidade, elasticidade causada por tensões diárias).

As cidades de Pedro Juan Caballero e Ponta Porã, terão sua fundação de fato como indicada nos parágrafos inicias marcados por um objetivo comum, por fins econômicos. $\mathrm{O}$ encontro de brasileiros e paraguaios obviamente causará o choque de identidades que passaram por um processo de reafirmação provocada pela "Guerra Guazú" (Guerra da Tríplice Aliança). De um lado os derrotados e do outro os "vencedores"

Não entrando no mérito de quem chegou primeiramente em uma das duas cidades, tema discutido e sustentado por historiadores sem chegar a um consenso, o que interessa é analisar os processos de Territorialização que de fato incidiram para a fixação e formação de uma sociedade fronteiriça. Cumprirá este papel em 1882 Tomáz Larangeira com a missão de explorar o cultivo e comercialização da erva-mate e exportar para a Argentina, consequentemente, gaúchos fazem parte desse processo instalando-se na região para o desenvolvimento da agricultura.

Do lado paraguaio, inicialmente a cidade de Pedro Juan Caballero, inicialmente chamada de Punta Porá, pertencia ao departamento de Concepción. Em 1889 um decreto presidencial autorizou a criação de uma delegacia de polícia, pela qual em 1901 a cidade passa a ser denominada Pedro Juan Caballero. No entanto, donos de grandes terras se instalaram na cidade para a exploração da erva-mate. Desde então, inicia-se o assentamento de brasileiros e paraguaios na fronteira, que iniciara timidamente ao redor da "Laguna" até formar a cidade conurbada que conhecemos hoje, incluindo nestes dois grupos os imigrantes 
asiáticos, árabes, africanos, americanos e alguns europeus.

É inevitável que as relações sociais se restrinjam a um território sem impactar do "outro" lado. As territorialidades transcendem os territórios envolvidos no âmbito: cultural, político, educacional, segurança pública, lazer, saúde, enfim, nos mais variados aspectos cotidianos. Essa relação de troca é resultado da complementaridade da fronteira, pelo qual cria condições de interdependência entre as duas cidades. No tocante ás políticas públicas, por exemplo, existem instituições governamentais que possuem uma jurisdição restrita pelo território e limite demarcado, não podendo atuar conforme as demandas das duas cidades.

Essa mobilidade criará dois referenciais territoriais através da migração diária entre as duas cidades para trabalhar, estudar ou manter relações de parentesco, criando o "brasiguaio" com características muito distintas daquele brasiguaio anterior. "Eu não sou brasileiro nem paraguaio", afirmei em uma entrevista sobre transnacionalismo. Este sentimento de possuir dois referenciais nos desloca para uma experiência tanto no campo material quanto na simbólica em que se abandona uma identidade e migramos à outra em questões de minutos dependendo da situação em que nos encontramos ou nos deslocamos de um país para outro conforme a realidade evidenciando ao caráter negociado da identidade.

Há identidades hibridas na fronteira, haverá casos em que se diluirão alguns aspectos culturais do Brasil com a do Paraguai e vice-versa, caracterizando assim, identidades transfronteiriças. Percebe-se também, igualmente, processos iniciais de formação das "identidades mães", a condição de mistura para a composição desta identidade transfronteiriça, a partir da situação de "fronteira".

A identificação com a fronteira está embutida em quase todos os aspectos da vida social dos moradores daqui. Cito alguns exemplos de estabelecimentos comercias que levam o nome "fronteira" do lado brasileiro e paraguaio: bares, salões de beleza, vidraçaria, mercados, lanchonetes, lojas de autopeças, padarias, sites, inclusive igrejas.

\section{"El pedrojuanino"}

Seria interessante antes de estudar o gentílico citado, conhecer alguns aspectos da cidade que formará o ser pedrojuanino. Digo ser porque não se nasce pedrojuanino e sim será resultado de uma construção temporal-espacial.

O paraguaio de Pedro Juan Caballero apresentará uma construção identitária um pouco diferente do Paraguaio do interior do país, devido à condição de fronteira, apesar do Paraguai possuir seu território cercado de fronteiras com a Argentina, Bolívia e Brasil pode se encontrar características mais "paraguaias", por exemplo, em Assunção. A forte influência do Brasil desde a fundação das duas cidades marcará de forma singular o pedrojuanino. Essa diferenciação do pedrojuanino com o asunceno $^{3}$, foi descrita por Osvaldo, pedrojuanino, comerciante de 38 anos, em uma conversa que surgiu na mesma loja após o passo de brasileiros que motivou as conversas relacionadas a este assunto, descreve assim:

El lenguaje: "yeismo" ellos dicen gayina, poyo, aya, como te yamas? etc.. (los pedrojuaninos no) porque ellos asimilan más argentina. Pero los pedrojuaninos Brasil. Los pedrojuaninos segúnlos linguistas expertos consiguieroncrearunlenguajeunico para la fronteracon Brasil...que es el"jopara", unlenguaje que surgio naturalmente del pueblo no como el de losasuncenosunlenguajeimitado,copiado y creadoen escritórios, no surgio del pueblo de la sociedad, sino imitado pirateado.

Vestimenta: tela, tendência, corte de pelos, maquillajes, todos argentinos.

\footnotetext{
${ }^{3}$ Gentílico de quem mora em Assunção.
} 
Pedrojuaninos no tanto algo si, pero no todo. Maquillaje mas suave natural sinpestañaspostizas, loshombres cortes de pelo, mas clasico. Obvio, me refiero en lo general

En la interaccion social: pedrojuaninos son mas hospitalarios los asuncenos mucho menos Influye un factor q interviene en la delincuencia, alla la delincuencia es mas violento por "poco" ahi entran los pirañitas, caballos locos, carteristas, peajeros, los chespis como ellos llaman, moto chorros (te clavan, te matan por poca cosa). los pedrojuaninos no tienen esos tipos de delincuentes aun, tiene pero muy poco aca es más entre los narcotraficantes. Auntenemoseso de compartir connuestrosvecinos una sopa, unbori, una chipa, permutar alimentos, allaellos nada nibollo, hoy dia claro enel contexto temporal actual.

Alimentación: Asuncenos mas comidas rápidas losllamados (faatfoots) Por que todo es lejos, entonces se come mas por los super comedores Pedrojuaninos, comidas caseras, porque es cerca llegar a casa y comer comidas de mama, comidas que no son industrializadas comerciales.

Temperamento:Asuncenos, mas estresados, bocinas, trafico vial, embotellamiento, bocinasos, etc..Pedrojuaninos, mas tranquilos, no tocanbocinas, mas cuidadosos, menos estresado y tal

Educacion financiera: Asuncenos tienen, más cuidados en los gastos, más "yopy"..porque alla si no tenespa tu pasaje no llegas a tu casa si te falta 200 gs Sim plata no sobrevivis. Pedrojuanino es mas compulsivo enlos gastos Porque es todo cerca Generalmentesiempreteniendoencuenta la variable (generalmente)

Estatus: abolengo, estratificacionn: Asuncenos en ciertos lugares públicos o privados no sos nadie si no tenes poder adquisitivo o si tus padres no te transmiten el estatus nadie ni bollo para nadie. (Osvaldo, 38 anos, pedrojuanino, comerciante, Pedro Juan Caballero, 25/05/2017).

Essas influências que Pedro Juan receberá de um lado de países que foram colonizados pelos espanhóis e de outro do lado brasileiro criará uma parcela de pedrojuaninos internacionalizado, moderno, exigente e inserido nos "gostos" que a modernidade oferece. Por outro, lado encontra-se o pedrojuanino excluído desses processos. Ao me posicionar como pesquisador a minha composição identitária remete muito à América Hispânica, devido à influência através de canais de televisão à cabo que do lado paraguaio é mais acessível, portanto, no tocante â informação, músicas por exemplo, essa universalização chega a mais pessoas do lado paraguaio.

Aqui faltaria espaço para exemplificar todos os trabalhos informais e essa forma de vida que se distingue da ponta-poranense, na zona sul de Pedro Juan Caballero, por exemplo, observa-se uma dinâmica não muito parecida ao centro da cidade, prevalecem características similares ao da capital, lojas das mais variadas desde alimentícias, têxtil, aparelhos eletrônicos, barbearias, mercados, restaurantes que abastecem o consumidor de Pedro Juan, não ao turista que permanece na área central, entende como um deslocamento do centro comercial preparado ao consumidor local.

Em outras palavras viver em Pedro Juan Caballero para a grande maioria é vista desde o ponto de vista momentâneo, o trabalho é visto como algo necessário, mas sem deixar de lado os momentos do tereré, dos eventos sociais, do domingo, dos aniversários e dias festivos. Esta visão conforme mencionei anteriormente não representa todo pedrojuanino, pois o ser "pedrojuanino" se construirá dependendo de que lado se nasceu, da exclusão ou classe mais abastada.

Contudo, a relação que se tem com o tempo e o trabalho não é uma relação muito amistosa deste lado da fronteira. O trabalho desta forma que se conhece introduzido em nossa 
sociedade, não condiz com o modo de vida que se herdou dos antepassados. Embora em outros tempos o não entendimento desta relação transformou em estigma e tristemente confundido e representado como preguiçosos que paira até a atualidade em relação aos pedrojuaninos.

Existe o pedrojuanino que usufrui dos luxos da modernidade, discotecas com música eletrônica, carros luxuosos, festivais na lagoa junto com os estudantes de medicina brasileiros, trabalhos formais, que somente compram no Shopping China, que não fala guarani, que também estuda medicina ${ }^{4}$, que mantêm os melhores restaurantes da cidade, que vai ao cassino, que viaja para Balneário Camboriú no final do ano, que também é brasileiro, que deve declarar imposto de renda no Brasil, etc.

Reconhecendo o avanço do sistema capitalista através da globalização, houve elementos culturais mantidos, no caso pedrojuanino, por exemplo, os costumes religiosos, a música tradicional paraguaia e o idioma guarani resistem para não desaparecer em meio a essa tentativa homogeneizadora globalizada.

Essas influências são trazidas do Brasil, países hispano-americanos e imigrantes que se fixaram na fronteira com suas culturas e que também se trouxe em outro momento em que se foi imigrante em outro lugar. Afinal em Pedro Juan há muitos retornados da Argentina e da Espanha que carregam consigo características absorvidas desses lugares e servem de distribuidores dessas culturas. Existe, no entanto, certezas, dúvidas, confusões que pairam na mente tanto do pedrojuanino quanto nas dos "rapai" aqui mencionados no tocante à identificação. Pensar identidade na fronteira requer imaginar aproximações e distanciamentos diários. Pois, a fragmentação da identidade inserida no sujeito híbrido, inacabado, resultado do movimento intenso destes entre os dois países (CANCLINI, 2003).

\section{Os "rapai"5 de Ponta Porã}

Por se tratar de uma cidade de fronteira seca, o que impera no imaginário da maioria das pessoas que visitam a cidade é de que aqui há uma cidade, integrada, "que não se percebe que são duas cidades". Embora as relações de vizinhança existem desde a formação das duas cidades as disparidades e afirmação do diferente estão presentes no cotidiano de todos os habitantes das cidades conurbadas.

Retomo aqui a discussão relacionada ao fronteiriço, vivenciar a fronteira exige um esforço muito grande de seus habitantes, devido às múltiplas identidades que viver na fronteira exige, máscaras que se utilizam em todos os aspectos da vida, seja, política, familiar e trabalhista. Possuir dois referenciais territoriais e viverem múltiplos espaços como em Estados diferentes pode criar crises de identidade. São realidades que a fronteira oferece. Também oportunidades para negociar a identidade, ora compensa ser brasileiro ora paraguaio, o comportamento e atitudes do pedrojuanino em relação aos "rapai" pode ser diferente em

\footnotetext{
${ }^{4}$ Atualmente não há um consenso enquanto ao número exato de estudantes de medicina nem fonte segura, há alguns que dizem ser 5.000 outros 6.000. o site da Terra fez uma publicação com 8.000 acadêmicos (TERRA, 2016) e 10. 000 segundo o site Campo Grande News em 2016. Mas fora os números, é entendível que o ingresso econômico que os cursos de medicina deixam na cidade é de suma importância para a economia da cidade. Desde o ramo imobiliário, comércio, mercados e bares noturnos. Em contrapartida os conflitos são diários, podemos citar alguns: estacionamentos, festas de calouros no centro comercial inviabilizam o trânsito e causa mal estar entre os comerciantes, casos de microtraficantes infiltrados como alunos, dentre outros problemas menores). Os problemas econômicos de alguns alunos sãoevidentes que buscam conciliar trabalho e estudo, casos de suicídio foi registrado recentemente de um acadêmico brasileiro em Pedro Juan Caballero por motivos desconhecidos.

${ }^{5}$ Rapai pronunciado "rapai” em português é o modo em que os pedrojuaninos se referem aos brasileiros.
} 
outro momento quando lida com outro pedrojuanino, nota-se dessa forma o caráter relacional da identidade.

Essa mobilidade ocorre ininterruptamente pelo fato desta fronteira ser aberta, e pelo fato do "outro" lado oferecer o que "nós" não temos e vice versa. A possibilidade de trocar as máscaras e assumir a outra identidade faz deste espaço um laboratório de experiências sociais dado à condição de fronteira que apresenta.

O fato de Ponta Porã não possuir a mesma quantidade de praças que Pedro Juan Caballero (cada bairro possui uma praça) faz que os ponta-poranenses utilizem bastante o Parque dos Ervais. Espaço de lazer, com área verde, quadras de vôlei, futebol, basquete, circuito para correr.

No tocante ao lazer noturno nos fins de semana, o fato de Ponta Porã não contar com nenhuma discoteca, a Avenida Brasil segue sendo um importante local de encontro da juventude ponta-poranense nos fins de semana. Há aproximadamente cinco bares-pubs do lado brasileiro, o que criar oportunidades para que os ponta-poranenses cruzem do lado paraguaio em busca de lazer.

\section{"Identidades de Gaveta"}

Neste item demostraremos casos de sujeitos que ao nascer foram registrados em dois municípios como meio de obter a dupla cidadania e/ou dupla nacionalidade. Iremos pensar a nacionalidade como processo de territorialização, pois a identidade neste caso é a nacionalidade ancorada no território (DORFMANN, 2008). É um assunto muito delicado na fronteira, pois ter o registro de nascimento sem de fato ter nascido no território, é considerado crime. Muitos os que fazem por motivos de parentesco, circunstâncias e outros em busca de benefícios como saúde, educação, negócios.

Contudo nem todos os sujeitos que possuem dupla nacionalidade possuem um sentimento de pertencimento com o outro território. Casos parecidos ocorrem na fronteira entre as cidades de Sant'Ana do Livramento e Rivera na fronteira entre Brasil e Uruguai. Como afirma Dorfmann:

Evidenciou-se em vários momentos a tensão entre o estatuto legal e a autoimagem, ou entre o institucionalizado e a prática cotidiana. A nacionalidade na fronteira Brasil Uruguai pode ser adquirida como uma estratégia na obtenção de vantagens locais, disponíveis na região, não necessariamente representando pertencimento à nação (DORFMANN, 2008, p. 268,).

Em Pedro Juan Caballero e Ponta Porã também se adquire a nacionalidade por ter nascido em solo brasileiro ou paraguaio e por herança. Se uma paraguaia entra em trabalho de parto em Ponta Porã, por exemplo, o nascido recebe a nacionalidade brasileira; logo será registrado no Paraguai e deve renunciar à essa nacionalidade optando por uma. "A legislação paraguaia não reconhece outras nacionalidades, se deve necessariamente optar por uma" (Atendente no guichê do consulado brasileiro, conversa realizada em 25/03/2018).

Já a brasileira que por ventura teve o filho nascido no Paraguai, e foi registrado ali, tem a possibilidade de legalizar o documento no Consulado deste país, onde este órgão emitirá uma certidão que deverá ser homologada em um cartório brasileiro e de imediato é emitida uma certidão de nascimento brasileira à criança. $\mathrm{O}$ Brasil reconhece e aceita mais de

\footnotetext{
${ }^{6}$ Neste item, se preservará o nome real dos entrevistados, local e situação da conversa por discrição, pedido pelos próprios entrevistados. Se lhes será atribuído nomes fictícios
} 
uma nacionalidade. Neste caso os pais deveriam avisar o Paraguai desse registro e cancelar o paraguaio (mas não é o que acontece).

Em uma conversa com Maria (brasileira), esta comenta esse caso:

A Júlia nasceu aqui no Paraguai, preferi o meu médico daqui; daí como o Juan é paraguaio, ele queria que registrasse ela aqui, então fomos registrar ela aqui mesmo. Depois quando precisei viajar ao Brasil tive que tirar a certidão dela como brasileira. Não quero mesmo que ela seja só paraguaia, acho melhor ela usar só a do Brasil. Passei no Consulado fiz a documentação e pronto. Agora ela tem os dois, mas não vou cancelar o paraguaio, vai que algum dia ela precisa (Maria, 24 anos, Pedro Juan Caballero, 10/12/2017).

Assim, percebemos que a nacionalidade muitas vezes não está necessariamente vinculada ao sentimento de pertencimento à nação, nem no sentido de naturalidade somente, e sim, como meio (estratégia) de obter vantagens locais como citado anteriormente por Dorfmann (2008).

Outra via de dupla nacionalidade é a via da ilegalidade. Os nascidos são registrados e nas duas cidades, inclusive com nomes diferentes para tentar evitar uma possível identificação futura. Em uma visita a um cartório de Pedro Juan Caballero, em conversa com uma colaboradora, a mesma afirma que:

Hay mucha duplicidad, son muchos que tienen los dos documentos, pero muchos están buscando resolver, tiene que renunciar allá, o acá. No adelanta engavetar! La policia ya no quita la cédula de identidad, quando es adulto es más difícil sacar. La criatura no puede nacer em dos lugares al mismo tempo, vale el primero que sacó!

Mucha gente tiene, muchos brasileiros, a Brasil le interessa que el paraguayo tenga cédula de Brasil porque si tienen título de eleitor, pueden votar. Pero es mejor solo tener de um lado despues vatener problemas (Joana, Pedro Juan Caballero, 10/02/2018). ${ }^{7}$

Mais adiante nas conversas Joana diz que é comum estes casos na fronteira, "la mayoria tiene" diz. E comenta que não é somente paraguaios buscando vantagens no Brasil, mas também brasileiros buscando futuras vantagens no Paraguai, como compra de imóveis e automóveis, essa prática independe as classes sociais. As camadas mais favorecidas também utilizam desse instrumento e não é possível mensurar ou qualificar onde compensa mais ou menos. A necessidade de se legalizar de um lado ou de outro dependerá da realidade e intenções de cada sujeito.

Acerca disso em uma entrevista a Olegário Campos, tabelião do município de Ponta Porã e no trabalho há 60 anos (muito brincalhão e atencioso) ao comentar esse caso a ele este diz:

Isso é um ato criminoso! Eles tentam de tudo, muitos não vêm de má fé, muitas vêm. Dizem que a criança nasceu em casa, muitas vezes escapa, as

\footnotetext{
${ }^{7}$ Tradução: "Há muita duplicidade, são muitos que tem os dois documentos, mas muitos estão buscando resolver, tem que renunciar lá ou aqui. Não adianta engavetar! A polícia já não tira a cédula de identidade, e quando for adulto é mais difícil de tirar. A criança não pode nascer em dois lugares ao mesmo tempo! Vale o primeiro que tirou".

"Muita gente tem, muitos brasileiros, ao Brasil interessa que os paraguaios tenham a cédula do Brasil, porque daí tiram título de eleitores e podem votar lá. Mas é melhor só ter de um lado pois depois terão problemas".
} 
testemunhas são bem treinadas.

Acompanhei o fechamento de alguns cartórios da região. Até os tabeliões faziam, mas não acredito que seja por prevaricação, creio que achava que era normal, tirar aquela certidão para o amigo político pegar um paraguaio aí e fazer a inscrição no título eleitoral, um dos motivos maiores era esse. $\mathrm{O}$ pessoal fazia por qualquer sapato velho e votava. Isso daí diminuiu muito, foi uma mudança radical! Mas admito pode haver passado pelo meu cartório ou outros sem notar. Mas o que tem mais é certidão falsa. (Este me mostra um documento falso apresentado com vários erros).

Os dois grandes fatores são ambição política e necessidade de ajuda do governo saúde, educação, bolsa família, bolsa escola, bolsa não sei o que. Isso aí se chama pobreza, miséria, esses benefícios não têm no Paraguai. Acho que não existe uma intenção criminosa de se registrar aqui, acho mais isso como infração. Não acho haja um amor, apego pelo Brasil e sim para o mantimento de currais eleitorais do outro lado (OLEGÀRIO, tabelião, brasileiro, Ponta Porã, 10/03/2018).

Segundo as autoridades citadas acima, era e talvez ainda seja uma prática comum na fronteira à extensão o lado paraguaio das campanhas eleitorais do lado brasileiro. Estes por experiência asseguram que essa prática foi fomentada por um certo tempo por próprios políticos do lado brasileiro. Dessa forma, registravam o paraguaio, logo emitiam o título de eleitor e em troca de ajudas financeiras obtinham os votos desses sujeitos. Além disso, essa prática servia como enriquecimento pessoal de muitos responsáveis pela emissão do documento na fronteira. Recordo de quando era criança e ouvia adultos (familiares e vizinhos) negociando certidões de nascimento e mencionando alguns lugares como pontos de emissão desse documento. Um aluno do ensino médio do Distrito de Sanga Puitã, no Brasil, fronteira com Zanja Pytá no Paraguai, ${ }^{8}$ resolveu contar seu caso abertamente na roda de conversa, pois a maioria se encorajou e contou os casos que conheciam.

José comenta:

Meu pai é paraguaio puro, tem documento brasileiro também, mas não usa. Eu nasci no Brasil, sou brasiguaio, porque eu só venho pra estudar aqui o resto tudo no Paraguai, falo guarani espanhol, aqui é melhor pra médico essas coisas. Lá é mais caro, ah minha mãe é brasileira! Eu nasci no Paraguai, fui registrado aqui, tenho certidão, mas nunca usei. Uso só a brasileira.

Durante a conversa intervém uma aluna ansiosa e diz:

Eu queria também! Não sei eu quero todo mundo tem, faz falta alguma hora precisa neh!

Ele segue: As vantagens são muitas, por exemplo, a carteira de habilitação do Paraguai, em caso de viagem, não precisa tirar licença. Mas eu não conto para ninguém, tem bastante gente que troca o nome e tem quem troca até o sobrenome. O lado ruim seria só se a polícia pegar, resto é de boa (José, 22 anos, estudante, brasiguaio, Ponta Porã, 10/03/2018).

Há de se ter em consideração que para que a carteira de habilitação do Paraguai seja reconhecida e de fato proporcione vantagens, o cidadão deve ser paraguaio e dirigir um veículo paraguaio. Não é permitido que um brasileiro utilize uma carteira de habilitação paraguaia.

Nota-se uma normalidade e banalidade nestes casos aqui na fronteira apesar de se

\footnotetext{
${ }^{8}$ Distrito localizado à 13 quilômetros de Ponta Porã
} 
manter no anonimato; o objetivo principal mais uma vez é para obter benefícios locais de ambos os lados, como por exemplo, o de conseguir a carteira de habilitação, bem mais barata do lado paraguaio. Chamou a atenção nesta roda de conversa o brilho no olhar dessa outra aluna que fez a intervenção, ela tinha muita vontade de estar nessa situação, parecia se sentir excluída nesta sociedade local por não ter a dupla nacionalidade, mesmo que de forma ilegal.

Assim nem todos tem essa possibilidade na fronteira, não se pode quantificar pois são situações anônimas, ocultas e misteriosas. Também é importante destacar que ao perguntar a estes a possibilidade de seguir com essa prática com seus filhos, todos respondem de forma afirmativa. Demonstrando que a opção de dupla nacionalidade é utilizada como meio e estratégia de vida.

Em um bar em Pedro Juan Caballero, conversando com amigos e alguns primos lancei a conversa da dupla nacionalidade e uns conhecidos assumiram ter dupla nacionalidade, um dele é o Mateus, que afirmou:

Eu tenho dois documentos, nasci em Pedro Juan Caballero, sou filho de brasileira e paraguaio, morei sempre em Pedro Juan Caballero, mas estudei no Brasil o que me faz sentir brasiguaio. Uso somente a certidão e RG brasileiro, o paraguaio guardo, se acaso precisar. Esses dias mesmo me ofereceram um trabalho em Assunção, mas não pude ir porque não contratam brasileiros. Daí foi o momento em que pensei em usar o documento paraguaio, mas tenho medo da polícia perguntar porque demorei tanto para tirar o RG. (Mateus, 32 anos, desempregado, Pedro Juan Caballero, 11/12/2017).

Assim como Mateus existem outros casos para citar neste trabalho, são essas situações que criam as identidades de gaveta, pois os sujeitos assumem somente uma identidade, enquanto a outra está "engavetada" ou guardada nos guarda roupas, como dizem. Seria como um "plano B" ou "trunfos" que muitos brasiguaios, paraguaios ou brasileiros possuem, identidades que denomino de gaveta.

No momento de seu nascimento muitas crianças são registradas em ambos os territórios como estratégias de vida. Geralmente se troca o segundo nome para evitar que em algum momento possam ser descobertos, cientes da ilegalidade desse ato. Digo de gaveta porque se assume uma identidade enquanto a outra fica guardada à espera de seu acionamento, e há outras nacionalidades expiradas que em muitos casos nunca são utilizadas.

Uma aluna da rede Estadual em um diálogo informal, durante o recesso das aulas confessa:

Tem gente que é aposentado no Brasil e no Paraguai, meu vizinho faz dessa forma, recebe a aposentadoria dos dois lados. É difícil que eles descubram, pois as pessoas trocam os nomes. Só que ninguém deda né! Mas é ilegal. Algumas pessoas sabem, mas ninguém vai denunciar. Eu moro no Brasil, mas não tenho essas coisas não, não tive sorte (Carla, 29 anos, brasileira, Ponta Porã, 10/03/2018).

Este é outro caso comum na fronteira, pessoas que trabalharam dos dois lados e recebem a aposentadoria de ambas as previdências. Há também idosos que recebem ajuda ou benefício dos dois lados, sem necessariamente ter contribuído com a previdência. Contudo, não é tão simples obter esse benefício do lado paraguaio devido à precarização do trabalho, daí a estratégia para lográ-lo. 


\section{Identidades Simultâneas9}

Aqui apresentaremos alguns casos de pessoas que possuem a dupla nacionalidade, mas que não são "engavetadas" e sim ativadas e usadas simultaneamente no dia a dia. Relataremos de que forma se dá, e em que situações utilizam cada identidade no território paraguaio e brasileiro.

Em outra roda de conversa, conversei com Tânia, esta nasceu na cidade de Pedro Juan Caballero, brasiguaia, casou-se com brasileiro e quando à pergunto sobre o uso de dois documentos, ao mesmo tempo ela diz:

Primero tenia la identidade paraguaya, luego iba casar em Brasil y aproveche para que mi mama me registro en Brasil. Ami no me facilitó em nada, yo solo queria ser brasileira porque mi mama era brasileira. Pero por trabajo conpensaba. Pero yo me identifico como brasiguaya, porque mi papa es paraguayo.

Yo trabajo em los dos lados, vendo ropa en Brasil, produtos, tengo mi tienda em Paraguay vivo em los dos lados. Mi situación se que es ilegal pero no me preocupa tanto porque trabajo normal, no soy bandido. Pero as veces me preocupa. Y votar yo voto enlos dos lados! Yo mas luego me interessa Brasil por mi trabajo por las cosas que vendo, cuenta em el banco y também quiero beneficiarme de las cosas de Brasil, aposentadoria y eso. La mayoria de las personas tienen dupla nacionalidade para malandraje pero yo no, yo para tarbajar. Por mi queria que las personas que trabajan de los dos lados como yo, deberian tenerlos benefícios de los dos lados. Em mi caso funcionan los dos. Pero queria legalizarme em realidade, lo que era uno solución acaba sendo um problema. Me preocupa um poco realmente. Pero yo ahora voy a ver si hay como legalizar voy a legalizar. (Tânia, 58 anos, brasiguaia, Pedro Juan Caballero, 02/03/2018). ${ }^{10}$

O caso de Tânia é um dos casos mais complexos que encontrei até o momento, ela possui bens dos dois lados da fronteira, trabalha dos dois lados, tem filhos registrados com o documento paraguaio e uns com documento brasileiro, ou seja, legalmente não são irmãos. Contudo o que chama a atenção, é como essa situação de anonimato, nos torna quase invisíveis dentro da fluidez na fronteira e sustenta essa multiplicidade identitária. E é esse trânsito, essas relações que constroem a identidade transfronteiriça, ancorada em vários referenciais territoriais.

Outro caso é relatado por Francisco, numa roda de tereré em frente de sua casa numa visita:

Assumo las das identidades al mismo tempo, desde hace mucho tempo, uso

\footnotetext{
${ }^{9}$ Neste item também os entrevistados receberão nome fictício, para preservar suas identidades.

10 Tradução: "Primeiro eu tinha o RG brasileiro, logo iria me casar no Brasil e aproveitei e minha mãe me registrou no Brasil. Pra mim não facilitou em nada, eu so queria ser brasileira porque minha mãe era brasileira. Mas por trabalho compensava. Mas eu em identifico como paraguaia porque meu pai é paraguaio".

"Eu trabalho nos dois lados, vendo roupa no Brasil, produtos, tenho minha loja no Paraguai e moro nos dois lados. Sei que minha situação é ilegal, mas não me preocupa tanto porque trabalho normal, não sou bandido. Mas as vezes me preocupa. E votar, voto nos dois lados. Eu mais me interesso mesmo Brasil só pelo trabalho, pelas coisas que vendo, conta no banco e também quero em beneficiar das coisas do Brasil, aposentaria essas coisas. A maioria das pessoas tem dupla nacionalidade para malandragem, mas eu para trabalhar. Para mim acho que as pessoas que trabalham dos dois lados deveriam ter os benefícios dos dois lados. No meu caso funcionam as duas. Mas na realidade gostaria de me legalizar, o que era uma solução acabou sendo um problema, Me preocupa um pouco realmente, mas agora vou ver se tem como me legalizar, vou me legalizar".
} 
los dos. Paraguayo solo uso para andar em Paraguay, para viajar, no hace falta permiso. O Brasileiro é mais para emergência essas coisas, hospital, carrego o paraguaio. $\mathrm{O}$ brasileiro mais pra benefício. Eu prefiro ter os dois mesmos, não pretendo cancelar (Francisco, 25 anos, paraguaio, pedreiro, Pedro Juan Caballero, 23/01/2018).

Francisco ao ser perguntado se fosse decidir qual escolheria diz que preferiria o Brasileiro, pelas vantagens que o Brasil oferece, em momento diz que é paraguaio, logo diz ser brasiguaio, demostrando o caráter relacional da identidade. Também não pretende se desfazer dessa situação, e comentou que seu filho já está registrado nos dois territórios.

Para Gerson,

Brasil pecheareco la che documento, mokoivevaaipuru. Por ejemploche petei persona ápe há outro persona amo. Chengoaipurumokoiveva a mbaapohagua. Paraguai peaipuru registro de conducir a viaja hagua, migracion no inchai. Arecoche CNH Brasilpeavei. Paraguaipe i cuentavenda pagai impuesto. Pero cheikatu a cancela ope Paraguaypegua há a heya la brasileiro a. La desventaja la ilegal. MOkoivea lado pe oi la ventaja. Amo eye libra impuestogui, nandeperseguiri brasileiro. Há apeoí hospital. Há amo Paraguaype y barato ve la luz há y (Gerson, 29 anos, autônomo, Pedro Juan Caballero). ${ }^{11}$

O interessante desta entrevista é que Gerson fala em guarani yopará. Gerson também usa a dupla nacionalidade para obter benefícios locais, como escapar de perseguições de polícias caso apresente os documentos brasileiros no Paraguai e vice-versa, escapar de altos impostos do Brasil, mas, reconhece também a desvantagem da ilegalidade.

Finalmente, chegaremos aos novos autodefendidos brasiguaios, estes são urbanos, frutos das relações com os múltiplos espaços, sujeitos que estão no "entre lugar" que estão em dois lugares ao mesmo tempo, ou em nenhum são vistos. Também devemos pensar que não há uma diferenciação nítida destes brasiguaios, pois estes se mesclam e estão na multiplicidade.

Identidades em constante construção e redefinição, num jogo de sobrevivência real, muitas vezes mortal, aqui também a fronteira oferece esse caminho o mundo da criminalidade, do legal-ilegal, do lícito e do ilícito. Mas também há a possibilidade para o bem de assumir duas ou mais identidades ou só uma essa a Brasiguaia proporcionada pelo lugar em que nascemos.

Outros motivos de usar dupla nacionalidade se faz necessário no caso de empresários que precisam de contas correntes no Brasil; estes para comprar produtos brasileiros e escapar da receita, compram do Brasil e vendem os produtos contrabandeados no Paraguai. Assim também ocorre do lado brasileiro, há casos de empresários que se beneficiam dos baixos juros do empréstimo do lado paraguaio para obter crédito para seus negócios.

\section{Para não concluir...}

A fronteira referida acima possui particularidades que exigirá um trabalho mais

\footnotetext{
${ }^{11}$ Tradução. "No Brasil eu tenho documento também, uso os dois. Por exemplo aqui eu sou uma pessoa e lá eu sou outra. Eu uso os dois para trabalhar. No Paraguai uso para tirar a carteira de habilitação para o Paraguai, daí migração não "enche o saco". Também tenho Carteira de habilitação no Brasil. Aqui no Paraguai é melhor, pagamos menos impostos. Mas também posso cancelar os documentos do Paraguai e deixar o brasileiro. A desvantagem é a ilegalidade. E a vantagem é que está dois lados. Lá me libro dos impostos (risos), os brasileiros não perseguem a gente. Mas aqui tem hospital grátis e lá a luz e a água é muito caro".
} 
extenso para desvendar os pormenores desse casamento entre Pedro Juan Caballero e Ponta Porã, uma relação que dura há mais de 113 anos, mas como toda relação possui suas tensões e complicações no relacionamento, também é necessário o diálogo constante entre os "rapai", "paraguaio" e os amantes envolvidos neste caso "os imigrantes". Essa relação de interdependência desencadeia problemas desde emissões de certidões de nascimento (a nacionalidade) até heranças perdidas por causa das nacionalidades duplas. Mas nesse entre meio existem as integrações entre as duas cidades, no plano educacional, na segurança pública como na saúde, para isso recorre-se desde estratégias bilatérias oficias ao "jeitinho" brasileiro e por que não o, "voy a ver que puedo hacer" paraguaio, afinal a questão da legalidade é o fantasma que assombra os dois países, pelo qual os Estados possuem uma clara deficiência estrutural, exigindo assim soluções práticas urgentes em casos de fronteira

Contudo, a fronteira segue sua trajetória, nem tudo está integrado e diluído, a diferença se afirma a cada dia, e no encontro entre elas é que se reinventam as identidades há paraguaios brasileiros, brasiguaios, imigrantes, "rapais", "mandioquero", "chipero", alguns apenas passam, invisíveis (prostitutas, malabaristas, traficantes,) muitos vivem na "linha", enfim, nesta multiplicidade Carmen dizia que "tem lugar pra todo mundo", é porosa, aberta mesmo! No entanto, a fronteira precisa ser pensada neste contexto, para todos.

\section{Referências}

ALBUQUERQUE, J. L. A dinâmica das fronteiras: os brasiguaios entre o Brasil e o Paraguai. São Paulo. Annablume, 2010.

BARTH, F. Grupos étnicos e suas fronteiras. In: POUTIGNAT, P. e STREIFF-FENART, J. Teorias da etnicidade da etnicidade da etnicidade da etnicidade da etnicidade. São Paulo: Unesp, 1998.

BAUMAN, Zygmunt. Identidade. Tradução de Carlos Alberto Medeiros. Rio de Janeiro: Jorge Zahar Editor, 2005.

CASTELL, M. O poder da identidade. (a era da informação: economia, sociedade e cultura). Tradução Klauss B. Gerhardt. Prefácio de Ruth C. L. Cardoso. São Paulo: Paz e Terra, v.2, 1999.

CANCLINI, N. G. A globalização Imaginada. São Paulo: Iluminuras, 2003.

CHELOTTI, M.C.; PESSÔA, V.L.S. Reterritorialização e Identidade Territorial: os camponeses construindo novas territorialidades na fronteira Brasil/Uruguai. Revista Obsrvatorio Geográfico América Latina. http://www.observatoriogeograficoamericalatina.org.mx/egal12/Geografiasocioeconomica/Ge ografiacultural/107.pdf . Acesso em 12/03/2017.

DORFMAN, A. Nacionalidade doble-chapa: novas identidades na fronteira BrasilUruguai. In: Alvaro Luiz Heidrich et al. (org.). A emergência da multiterritorialidade: a ressignificação da relação do humano com o espaço. Porto Alegre , p. 241-270, 2008. Disponível em: Grupo Retis/UFRJ. Disponível em: http://www.retis.igeo.ufrj.br/pesquisa/limites-e-fronteiras-internacionais/nacionalidade-doblechapa-novas-identidades-na-fronteira-brasil-uruguai/\#.W4YKuehKjIU Acesso em: $10 / 03 / 2018$. 
HAESBAERT, R. (2004). O mito da desterritorialização: do "fim dos territórios" á multilateralidade. Rio de Janeiro, Brasil: Bertrand Brasil.

Identidades territoriais. In: ROSENDAHL, Z.; CORRÊA, R. L. (Org.) Manifestações da culturano espaço. Rio de Janeiro: Eduerj, 1999. p. 169-190.

.; MONDARDO, M. Transterritorialidade e antropofagia: territorialidades de trânsito numa perspectiva brasileiro-latino-americana. Revista GEOgraphia, Niterói: RJ, Vol. 12, No 24, 2010. Acesso em 12/06/2017.

HALL, S. A identidade cultural na pós-modernidade. 2. ed. Rio de Janeiro: DP\&A, 1998.

LACLAU, Ernesto. New Reflections on the Revolution of Our Time. London: Verso,1990.

MARTIN, André Roberto. Fronteiras e nações. 4.ed. São Paulo: Contexto, 1998.

MARTINS, José de Souza. Fronteira: a degradação do Outro nos confins do humano. São Paulo: Ed. Contexto, 2009.

SILVA, Tomaz Tadeu da. Identidade e diferença: a perspectiva dos estudos culturais/ Tomaz Tadeu da Silva (org.) Stuart Hall, KathrynWoodward. Petrópolis, RJ: Vozes, 2000.

\section{Nota biográfica:}

Jonas Ariel Cantaluppi de Souza: Possui graduação em Geografia pela Faculdade de Ponta Porã. É especialista em Educação para a Infância: Educação Infantil e séries iniciais pelas Faculdades Integradas do Vale do Ivaí. Mestrado em Geografia pela Universidade Federal da Grande Dourados. Possui experiência na docência do Ensino Fundamental, médio e Educação para Jovens e Adultos. Realiza pesquisa nas áreas de território; identidade; migração e fronteira. Atualmente é coordenador de projetos culturais na Fundação da Cultura de Ponta Porã e Técnico em Geografia na Secretaria Municipal de Educação. Integra a Comissão Editorial da Revista Latino-americana de Estudantes de Geografia RELEG. 